\title{
Socio-Demographic Determinants of Road Traffic Fatalities in Women of Reproductive Age in the Republic of Georgia: Evidence from the National Reproductive Age Mortality Study (20I4)
}

This article was published in the following Dove Press journal:

International Journal of Women's Health

\begin{abstract}
Nino Lomia (D)
Nino Berdzuli (D)

Nino Sharashidze (iD ${ }^{2}$

Lela Sturua $^{3}$

Ekaterine Pestvenidze (iD)

Maia Kereselidze ${ }^{4}$

Marina Topuridze 5

Babill Stray-Pedersen (1D) ${ }^{6, \dagger}$

Arne Stray-Pedersen (iD)

'Institute of Clinical Medicine, Faculty of Medicine, University of Oslo, Oslo,

Norway; ${ }^{2}$ Department of Clinical and Research Skills, Faculty of Medicine, Iv. Javakhishvili Tbilisi State University, Tbilisi, Georgia; ${ }^{3}$ Department of Noncommunicable Diseases, National Center for Disease Control and Public Health, Tbilisi, Georgia; ${ }^{4}$ Department of Medical Statistics, National Center for

Disease Control and Public Health,

Tbilisi, Georgia; ${ }^{5}$ Health Promotion

Division, Department of

Noncommunicable Diseases, National

Center for Disease Control and Public

Health, Tbilisi, Georgia; ' $D$ epartment of Obstetrics and Gynecology,

Rikshospitalet, Oslo University Hospital, and Institute of Clinical Medicine, Faculty of Medicine, University of Oslo, Oslo, Norway; ${ }^{7}$ Department of Forensic Sciences, Oslo University Hospital, Institute of Clinical Medicine, Faculty of Medicine, University of Oslo, Oslo, Norway
\end{abstract}

${ }^{\dagger}$ Dr Babill Stray Pedersen passed away on 24 April, 2019

Correspondence: Nino Lomia

Emailninolomia@yahoo.com
Purpose: Globally and in the European region, the road traffic injuries (RTI) have emerged as a major public health and development problem, killing the most productive adult members of a population, including women. This study aimed to identify the key sociodemographic determinants of premature and avoidable RTI mortality in reproductive-aged women (15-49 years) in Georgia.

Materials and Methods: The study employed verbal autopsy data from the second national reproductive age mortality survey (RAMOS 2014). Univariate and multivariate logistic regression models were fitted using the Firth method to assess the crude and adjusted effects of each individual level socio-demographic factor on the odds of RTI-attributed death, with corresponding 95\% confidence intervals (COR and AOR, 95\% CI).

Results: Of 843 women aged 15-49 years, 78 (9.3\%) were the victims of fatal traffic crashes. After multivariate adjustment, the odds of dying from RTI were significantly higher in women aged $15-29$ years $(\mathrm{AOR}=7.73,95 \% \mathrm{CI}=4.20$ to 14.20$)$, those being employed $(\mathrm{AOR}=2.11,95 \% \mathrm{CI}=1.22$ to 3.64$)$ and the wealthiest $(\mathrm{AOR}=2.88,95 \% \mathrm{CI}=1.44$ to 5.77$)$ compared, respectively, to their oldest (40-49 years), unemployed and poorest counterparts. Conversely, there were no statistically significant ethnic, marital, rural/urban, and educational disparities in women's RTI fatalities. Overall, motorized four-wheeler occupants $(78.2 \%)$, particularly passengers $(71.8 \%)$, appeared to be the most common victims of fatal road injuries than pedestrians $(20.5 \%)$. Alarmingly, the vast majority $(85.9 \%)$ of any type of road users died instantly at the scene of collision, as compared to deaths en route to hospital $(1.3 \%)$ or in hospital $(11.5 \%)$.

Conclusion: Age, employment, and wealth status appeared to be the strong independent predictors of young women's RTI mortality in Georgia. Future comprehensive research would be advantageous for further deciphering the differential impact of social determinants on traffic-induced fatalities, as a vital platform for evidence-based remedial actions on this predictable and preventable safety hazard.

Keywords: women's health, road traffic injuries, mortality, socioeconomic factors, employment, wealth status

\section{Introduction}

The road traffic injuries (RTIs) have emerged as a major public health and development problem on the global landscape killing 1.35 million people annually on world's roads, with low- and middle-income countries (LMICs) disproportionately 
sharing $93 \%$ of this burden as an inevitable and destructive side-effect of rapid urbanization and motorization, compounded by the lack of adequate road safety policies and strategies in place. ${ }^{1,3}$ The global breakdown of road traffic deaths by road user group reflects the dramatic variation across country income levels, indicating a clear preponderance of vulnerable road users such as pedestrians and cyclists in LMICs, as opposed to car occupants in HICs. ${ }^{1,3}$ Projections suggest that unless immediate action is taken, road traffic accidents will climb up from its present global ranking of eights position to the seventh as a leading cause of death by 2030 , with LMICs anticipated to be entirely responsible for this rise. ${ }^{1}$ Apart from the staggering human toll of traffic crashes on lives of the most productive adult members of a population (15-44), the road casualties entail the major financial impact on individual families and national economies, costing approximately 3\% of Gross Domestic Product (GDP), which rises to $5 \%$ in LMICs. ${ }^{1,3,4}$ Worldwide, including in the WHO European region, RTIs are now the leading cause of mortality in adolescents and young adults aged 15-29 years and one of the top five causes of death among women in the age range of 15-49 years. ${ }^{1,6}$

It has been widely acknowledged that RTI is a multifaceted phenomenon, influenced by a complex interplay of a myriad of fundamental dimensions like population density and structure, motorization, nature of traffic mix, urbanization rate, road and other transport infrastructures, general safety measures, vehicular and behavioral factors, and environmental externalities in conjunction with accessibility and quality of definitive medical care at pre-hospital and hospital levels. ${ }^{1,3,4,7}$ The growing body of empirical evidence, though, consistently highlights that individual socioeconomic position (SEP) may also play a major role in determining the magnitude, pattern, severity and outcome of this unintentional road trauma at the country level. ${ }^{3,7,10}$ Indeed, accumulated research within and outside of the European context consistently supports that vulnerability, exposure, and consequences of traffic-related injuries are differently borne by the different socioeconomic strata, with people of lower SEP such as lower levels of education, income, and low-status occupation tending to face a greater risk of incurring both fatal and non-fatal RTIs compared to more advantaged members of society, which is also true for inequalities governed by various demographic factors, including, age, race/ethnicity, marital status, and place of residence. ${ }^{3,7,11}$ However, while the current evidence stems mostly from HICs, including within Europe, there is a stark paucity of the population-based studies assessing the socioeconomic distinctions of RTI victims, notably females, in LMICs, wherein the persistent lack of reliable and systematic data thwarts the recognition of this growing public health threat on the national scale, affecting thereby evidence-based policy development. ${ }^{3,9,11,12}$ The former Soviet Union (FSU) countries, like Georgia, are no exception to the above., ${ }^{4,12,15}$

Georgia, a middle-income country in the Caucasus Region of Eurasia, with an estimated population of four million, has witnessed the dramatic increase in the RTI mortality rates since the dissolution of the Soviet Union, coinciding with the profound and at times turbulent socioeconomic transformation occurring during the transitional period to post-communism. ${ }^{1,2,4,16,17}$ In spite of some recent governmental efforts to improve countrywide the road infrastructure and bring road safety legislation on speed limits, drunk and distracting driving, and mandatory use of seat belts and helmets in line with the best practice, the intensity of traffic law enforcement and investment in road safety interventions are as yet not commensurate with the scale of the problem, ${ }^{1,17}$ ranking Georgia among the WHO European region top 12 countries with the highest RTI mortality rates. ${ }^{4}$ The neglected incongruity between the unabated trends in fatal traffic injuries and effective response has been reflected in the findings from the two national reproductive age mortality surveys (RAMOS 2008 and RAMOS 2014), documenting the significant underestimation of RTI-related deaths in routine statistics, while also identifying RTIs as the second leading cause of death in women of reproductive age (15-49 years) and the principle cause of death among those aged 15-35 years both in 2006 and 2012, with a worrying mortality plateau over this period of time. ${ }^{18,19}$ Such a disturbing trend brings into focus the need for research-based and contextsensitive countermeasures to curb RTI epidemics and thus, redress social injustice in this area.

Consistent with this need, the present study sought to explore the major socio-demographic determinants of RTIattributed mortality in women of reproductive age (15-49 years) who died in Georgia in 2012, using the data from the second RAMOS 2014, conducted by the National Center for Disease Control and Public Health (NCDC\&PH).

\section{Materials and Methods}

\section{Study Population and Data Sources}

The data for the repeat national RAMOS 2014 were collected from March to December 2014 through the verbal 
autopsy (VA) interviews with family members or other close caregivers of all deceased women aged 15-49 years, identified based on multiple sources of mortality data available in Georgia for the year 2012 Information on premortem illness signs and symptoms, as well as socio-demographic characteristics and place of death was obtained by skilled interviewers using the VA instrument developed for the first national RAMOS $2008 .{ }^{18,19}$ Of the 913 eligible deaths, 878 VAs were successfully completed, thus yielding a response rate of $96.2 \%$.

Physician-certified VA (PCVA) approach was used to assign the most probable underlying cause to each death using the International Classification of Diseases, 10th revision (ICD-10). ${ }^{20}$ The detailed data collection and cause-ofdeath certification approaches for the RAMOS 2014 have been previously described elsewhere. ${ }^{19}$

\section{Variables}

The main study outcome was a death from RTI sustained by road users in motor vehicle collision and non-collision events. For the purposes of our analysis, RTI-related death is considered as a binary dependent variable (Yes/No).

Selection of demographic and socioeconomic indicators was guided by previous studies on this topic and included women's age (15-29, 30-39, and 40-49 years), ethnicity (Georgian, and ethnic minorities), marital status (unmarried, including divorced, separated and widowed, and currently married), educational attainment (incomplete secondary, and complete secondary or higher, including technical college and university), as well as the current employment status (employed and unemployed, including students). The composite wealth index, developed based on the ownership of household durable assets, housing characteristics and services (TV, refrigerator, landline and mobile telephone, video player, car, vacation home, housing tenure, room number, roofing materials, cooking fuel, electricity, water supply, and sanitation facilities), served as a proxy for household wealth status (poor, middle, and rich). All variables were either based on the original coding or aggregated into broader categories to increase the power for the study. Simultaneously, the role of victims in road traffic accidents and their place of death were also evaluated.

\section{Statistical Analysis}

Principal component analysis (PCA), specifically the first principal component, was employed to construct an asset- based composite wealth index as a proxy measure of wealth status for each household, who were subsequently ranked into wealth tertiles, as poor, middle, and rich. ${ }^{21}$

The findings for selected variables (all coded categorically) were summarized using descriptive statistics. Records with missing data were removed from the analysis $(n=35,<5 \%)$. Proportions were compared using the Pearson's chi-square test or Fisher's exact test, as appropriate. Univariate and multivariate models were then fitted to explore the associations between individual-level sociodemographic indicators and RTI mortality using the Firth method, a penalized maximum likelihood estimation approach applied to logistic regression for reducing the small sample bias in maximum likelihood estimation given the relatively rare events in our data. ${ }^{22}$ The results of regression analyses were reported as crude and adjusted odds ratios with corresponding $95 \%$ confidence intervals (COR and AOR, 95\% CI). A two-tailed p-value of $<0.05$ was considered statistically significant. All the analyses were performed using SPSS version 21.0 (IBM SPSS Statistics for Windows, Version 21.0. Armonk, NY: IBM Corp.) and Stata version 14.2 (StataCorp LP, College Station, TX, USA).

\section{Ethical Consideration}

Ethical clearance for this study was received from the Institutional Review Board of the NCDC\&PH and the Regional Committees for Medical and Health Research Ethics South East Norway. Written informed consent was obtained from all respondents prior to interviews. The study protocol and conduct adhered to the principles laid down in the Declaration of Helsinki.

\section{Results}

\section{Characteristics of the Study Population}

The final sample comprised 843 women of reproductive age (15-49 years), of which 78 (9.3\%) were the victims of fatal traffic injuries, with mean age at death $32.1 \pm$ 9.8 years (Table 1). Figure 1 illustrates the percentage distribution of RTI deaths by road user type (A) and place of death (B). As can be seen, traffic-induced fatal injuries were far more common among motorized fourwheeler (car) occupants $(61,78.2 \%)$ as passengers (56, $71.8 \%)$ and as drivers $(4,5.1 \%)$ than in pedestrians as vulnerable road users $(16,20.5 \%)$. Light vehicles (cars and vans) have been identified as the most common offending agents accounting for $81.0 \%$ (13) of pedestrian 
Table I Socio-Demographic Determinants of Road Traffic Fatalities in Women of Reproductive Age Who Died in 2012: Georgia RAMOS 2014

\begin{tabular}{|c|c|c|c|c|c|c|c|c|}
\hline $\begin{array}{l}\text { Socio-Demographic } \\
\text { Characteristics }\end{array}$ & $\begin{array}{l}\text { Total } \\
\text { Deaths } \\
(\mathrm{N}=\mathbf{8 4 3})\end{array}$ & $\begin{array}{l}\text { RTI } \\
\text { Deaths } \\
(\mathrm{N}=78)\end{array}$ & $\begin{array}{l}\text { Non-RTI } \\
\text { Deaths } \\
(\mathrm{N}=765)\end{array}$ & P-value & COR & P-value & AOR & P-value \\
\hline & $\%(n)$ & $\%(n)$ & $\%(n)$ & & $(95 \% \mathrm{Cl})$ & & $(95 \% \mathrm{Cl})$ & \\
\hline $\begin{array}{l}\text { Age (years) } \\
\begin{array}{l}15-29 \\
30-39 \\
40-49\end{array}\end{array}$ & $\begin{array}{l}16.1(136) \\
23.6(199) \\
60.3(508)\end{array}$ & $\begin{array}{l}42.3(33) \\
29.5(23) \\
28.2(22)\end{array}$ & $\begin{array}{l}13.5(103) \\
23.0(176) \\
63.5(486)\end{array}$ & $<0.001 * *$ & $\begin{array}{l}7.00(3.94 \text { to } 12.44) \\
2.88(1.58 \text { to } 5.26) \\
\text { Reference }\end{array}$ & $\begin{array}{l}<0.001^{* *} \\
0.001^{*}\end{array}$ & $\begin{array}{l}7.73(4.20 \text { to } 14.20) \\
2.82(1.52 \text { to } 5.20) \\
\text { Reference }\end{array}$ & $\begin{array}{l}<0.001^{* *} \\
0.001^{*}\end{array}$ \\
\hline $\begin{array}{l}\text { Ethnicity } \\
\text { Georgian } \\
\text { Other }\end{array}$ & $\begin{array}{l}83.2(701) \\
16.8(142)\end{array}$ & $\begin{array}{l}76.9(60) \\
23.1(18)\end{array}$ & $\begin{array}{l}83.8(641) \\
16.2(124)\end{array}$ & 0.151 & $\begin{array}{l}\text { Reference } \\
1.58(0.91 \text { to } 2.75)\end{array}$ & 0.108 & $\begin{array}{l}\text { Reference } \\
1.76(0.94 \text { to } 3.29)\end{array}$ & 0.075 \\
\hline $\begin{array}{l}\text { Marital status } \\
\text { Never or formerly } \\
\text { married } \\
\text { Currently married }\end{array}$ & $\begin{array}{l}40.5(34 I) \\
59.5(502)\end{array}$ & $\begin{array}{l}44.9(35) \\
55.1(43)\end{array}$ & $\begin{array}{l}40.0(306) \\
60.0(459)\end{array}$ & 0.400 & $\begin{array}{l}\text { Reference } \\
1.22(0.77 \text { to } 1.95)\end{array}$ & 0.397 & $\begin{array}{l}\text { Reference } \\
1.13(0.68 \text { to } 1.86)\end{array}$ & 0.638 \\
\hline $\begin{array}{l}\text { Place of residence } \\
\text { Urban } \\
\text { Rural }\end{array}$ & $\begin{array}{l}59.2(499) \\
40.8(344)\end{array}$ & $\begin{array}{l}56.4(40) \\
43.6(34)\end{array}$ & $\begin{array}{l}59.5(455) \\
40.5(310)\end{array}$ & 0.629 & $\begin{array}{l}\text { Reference } \\
\text { I.14 (0.7। to I.82) }\end{array}$ & 0.589 & $\begin{array}{l}\text { Reference } \\
1.36(0.83 \text { to } 2.25)\end{array}$ & 0.224 \\
\hline $\begin{array}{l}\text { Education } \\
\text { Secondary } \\
\text { incomplete } \\
\text { Secondary } \\
\text { completed and higher }\end{array}$ & $\begin{array}{l}28.8(243) \\
71.2(600)\end{array}$ & $\begin{array}{l}25.6(20) \\
74.4(58)\end{array}$ & $\begin{array}{l}29.2(223) \\
70.8(542)\end{array}$ & 0.600 & $\begin{array}{l}1.18 \text { (0.69 to } 1.99) \\
\text { Reference }\end{array}$ & 0.547 & $\begin{array}{l}1.10(0.58 \text { to } 2.10) \\
\text { Reference }\end{array}$ & 0.770 \\
\hline $\begin{array}{l}\text { Employment status } \\
\text { Employed } \\
\text { Unemployed/ } \\
\text { Housewife }\end{array}$ & $\begin{array}{l}25.9(218) \\
74.1(625)\end{array}$ & $\begin{array}{l}35.9(28) \\
64.1(50)\end{array}$ & $\begin{array}{l}24.8(190) \\
75.2(575)\end{array}$ & $0.041 *$ & $\begin{array}{l}1.71 \text { ( } 1.05 \text { to } 2.78) \\
\text { Reference }\end{array}$ & $0.032 *$ & $\begin{array}{l}2.11 \text { ( } 1.22 \text { to } 3.64) \\
\text { Reference }\end{array}$ & $0.007^{*}$ \\
\hline $\begin{array}{l}\text { Wealth status } \\
\text { Poor } \\
\text { Middle } \\
\text { Rich }\end{array}$ & $\begin{array}{l}32.1(271) \\
33.6(283) \\
34.3(289)\end{array}$ & $\begin{array}{l}19.2(15) \\
28.2(22) \\
52.6(41)\end{array}$ & $\begin{array}{l}33.5(256) \\
34.1(261) \\
32.4(248)\end{array}$ & $0.001 *$ & $\begin{array}{l}\text { Reference } \\
1.42(0.73 \text { to } 2.78) \\
2.76(1.50 \text { to } 5.08)\end{array}$ & $\begin{array}{l}0.301 \\
0.001 *\end{array}$ & $\begin{array}{l}\text { Reference } \\
1.51 \text { ( } 0.75 \text { to } 3.08) \\
2.88(1.44 \text { to } 5.77)\end{array}$ & $\begin{array}{l}0.252 \\
0.003^{*}\end{array}$ \\
\hline
\end{tabular}

Note: *p-value $<0.05 ; * *$ p-value $<0.001$.

Abbreviations: AOR, adjusted odds ratio; COR, crude odds ratio; RAMOS, reproductive age mortality survey; RTI, road traffic injury.

deaths, and the leading crash counterparts causing 39.3\% (24) of vehicle occupants' deaths, followed by heavy transport vehicles and buses (data not shown). Most victims $(67,85.9 \%)$ died instantly at the scene of collision, as compared to deaths occurring en route to hospital (1, $1.3 \%)$ or after arrival at hospital $(9,11.5 \%)$.

The socio-demographic characteristics of fatally injured decedents are presented in Table 1. An excess RTI mortality was identified in the youngest women aged 15-29 years (42.3\%) with respect to almost equally affected older age groups. Compared to ethnic minorities, fatal traffic injuries were much more prominent among native Georgians $(76.9 \%)$, with a less distinct predominance seen in currently married $(55.1 \%)$ and urban women $(56.4 \%)$ relative to their unmarried and rural counterparts. Surprisingly, women with higher SEP, in particular, those with higher education (74.4\%) and wealth status (52.6\%), appeared to be among the primary RTI victims, unlike their less literate $(25.6 \%)$ and affluent (28.2\% and $19.2 \%$ ) peers. By contrast, employed women (35.9\%) seemed to be less involved in fatal road crashes than their unemployed counterparts (Table 1).

\section{Predictors of RTI-Attributed Mortality}

Table 1 summarizes the results of the univariate and multivariate regression, showing the crude and adjusted effects of 


\section{A. Road users ( $n=78)$}

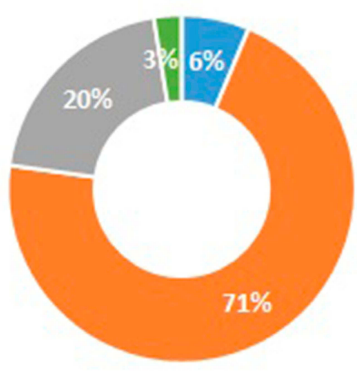

- Cardriver " Passenger " Pedestrian " Other

\section{B. Place of death $(n=78)$}

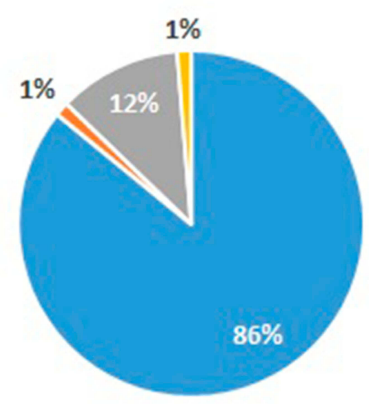

n On scene $=$ En route $=$ Hospital $=$ Other

Figure I Percentage distribution of RTI deaths by road user type $(\mathbf{A})$ and place of death $(\mathbf{B})$.

each selected risk factor on the odds of RTI-attributed death As shown in the final multivariate model, age, employment, and wealth status were the strong independent predictors of women's RTI mortality during their reproductive years. In particular, tending to significantly decrease with advance in age, the odds of being fatally injured peaked in women in the $15-29$ age range, yielding $7.73(95 \% \mathrm{CI}=4.20$ to 14.20 ; $\mathrm{p}<0.001)$ times as high as that for the oldest age group (40-49 years) once all other effects were controlled. The statistically significant reverse gradient for employment status detected in the univariate model found to become steeper and stronger upon multivariate adjustment, with working women emerging $2.11(95 \% \mathrm{CI}=1.22$ to $3.64 ; \mathrm{p}=0.007)$ times more likely to sustain fatal RTI than their unemployed counterparts. The similar positive trend was also seen across the wealth tertiles, indicating a rise in the odds of fatal traffic trauma with the increase in the wealth index level, yet this effect only reached statistical significance for the most affluent women, exhibiting almost three times greater odds than their poor peers $(\mathrm{AOR}=2.88 ; 95 \% \mathrm{CI}=1.44$ to 5.77 ; $\mathrm{p}=0.003$ ).

Conversely, although ethnic minorities, married, rural, and less educated women tended to have the higher odds of being victimized in traffic crashes compared, respectively, to their native Georgian, unmarried, urban, and more literate counterparts, none of these effects appeared to be statistically significant either before or after mutual adjustment (Table 1).

\section{Discussion}

Robust epidemiological research that can assess the magnitude and key determinants of RTIs is essential to determine, refine, and prioritize context-specific road safety initiatives that are affordable and widely applicable, and could potentially effectively avert associated fatalities. The present study identified younger age, and being from higher SEP categories such as employed and more affluent, as the strong independent predictors of fatal traffic injuries among women of reproductive age (15-49 years) in Georgia.

We found that four-wheeled motor vehicle occupants, notably car passengers, were the road user groups far more commonly involved in fatal traffic crashes, followed by pedestrian vulnerable road users, which is comparable with WHO estimates for Georgia and the European region, including the FSU, were car occupants make up about half of all RTI fatalities. ${ }^{1,4}$ This arguably reflects the predominant forms of mobility in the country, in general, stemming from the rapid expansion of motorization and increased car dependency for work- and non-workrelated activities, ${ }^{1,4,12,14}$ and female mobility, in particular, with women, compared to men, being less likely to own or drive cars and nearly unlikely to ride a bicycle or motorcycle due to underling sociocultural reasons. ${ }^{10}$

Particularly alarming is exceedingly high occurrence of on-scene traffic-related deaths $(86 \%)$, mirroring the evidence from India. ${ }^{23}$ This is indicative of slow progress in a sustainable and systemic national response to multiple road safety risks influencing both crash severity (eg, excessive speed, drink driving, seatbelt nonuse, substandard vehicles, and road infrastructure) and post-crash injury outcome (eg, delayed response time and the lack of quality pre-hospital care). ${ }^{1,4,17}$ Even though the proportion of injured people who die before reaching a hospital 
in LMICs is over twice that in $\mathrm{HICs},{ }^{1}$ high prehospital injury mortality rates have been also reported from the developed parts (mostly rural) of Europe, suggesting timely and effective emergency care at the scene, including by trained first responders, and prompt transport to closest trauma center to be an essential component of a safe system, with a serious impact on potentially preventable RTI deaths. ${ }^{1,24,25}$

Not surprisingly, our analysis discovered women in the youngest age group (15-29 years) to have the higher odds of dying on the roads compared to their older counterparts, which is in line with the extensive volume of global and European research, demonstrating the overrepresentation of adolescents and young adult people in their second and third decades of life in fatal traffic crashes, irrespective of the country income level. ${ }^{1,2,4,9,26,27}$ It has been suggested that, unlike the influence of cognitive development in children, "sensation seeking" behavior may lead to risktaking behavior in this age group, further aggravated by inexperience and susceptibility to peer pressure., $9,26,27$ Given the observed predominance of car passengers as RTI victims, our finding could be partially explained by the well-documented high level of peer influence between young drivers and passengers, regardless of their gender makeup. ${ }^{26,28,30}$ In particular, evidence suggests that the presence and the number of peer passengers increase the risk of their involvement in serious and fatal traffic crashes most likely caused by young and novice male drivers, triggered by explicit or implicit encouragement of risk taking (speeding, recklessness, illegal maneuvers, seat belt non-use, or disregard for other traffic regulations) and distraction (interior non-driving activity, including cell phone use, or exterior factors), ${ }^{28,29}$ while conversely, young drivers' high-risk behaviors may spillover to adversely affect passenger safety restraint use. ${ }^{30}$ This is further precipitated by the young drivers' lack of experience to handle hazardous situations, alongside their greater propensity for alcohol/drug consumption and night driving. ${ }^{26,28,30,32}$ The similar "sensation" and thus riskseeking behavior has been also reported among young pedestrians, including while crossing a road., 9,33,34 For instance, using planned behavior theory to explore midblock crossing behavior, studies from Chile and the US identified young pedestrians (between 17 and 30 years), irrespective of gender, to be more likely than their older counterparts to commit violations, errors, and lapses given their more positive attitude towards illegal crossing and intention to commit such violations. ${ }^{33,34}$ This troubling trend reaffirms that remedial actions ought to be geared towards improving legislative, infrastructure (eg, traffic separation and calming, signalized and zebra pedestrian crossing), education, and public awareness-raising interventions with a greater focus on young road users. ${ }^{9,13,15,35}$ While graduated licensing schemes may also provide an efficient avenue towards the prevention of risky road use and fatal or severe traffic crashes in young adults, ${ }^{27,28,35}$ it seems critical the seat-belt law in Georgia to cover not only front but also rear seat occupants, with a potential to reduce fatal injuries by up to $25 \%$ when combined with strong and sustained enforcement. ${ }^{1,19}$

The observed evidence of a non-significant association between ethnic background and fatal traffic injuries echoes the results from previous national cohort studies in Switzerland and Sweden, showing country of origin to have no strong effect on RTI mortality, ${ }^{36,37}$ which is also true for the flat ethnic/racial gradient derived from the US nationally representative study. ${ }^{11}$ This pattern has been supported by the longitudinal evidence from Netherlands for female victims overall, including car occupants, and 15-24-year age group, but not for female pedestrians and those aged 25-49 years, with the ethnic minorities' strong disadvantage. $^{38}$ Likewise, one US study identified the paradoxically blunted mortality gradient for Hispanic female car occupants (25-64 years) relative to their White counterparts, revealing though excess mortality among black women largely due to seat-belt underuse. ${ }^{39}$ However, other publications from the US, ${ }^{9,10}$ as well as New Zealand ${ }^{40}$ supported strong ethnic differentials in adverse RTI outcomes, largely skewed towards relatively more disadvantaged ethnic minorities, while also pointing to highly interlinked cultural characteristics and SEP as the most likely mechanisms shaping local experiences of exposure to traffic-induced injury. It has been suggested, though, that culturally determined behaviors such as risk taking, law compliance, supervision of children, or drinkdriving can still explain an important part of the ethnic variation in crash risks. ${ }^{7,9,10}$ For example, the "culture of alcohol", thus excessive alcohol intake among Russians and Slavs, in general, has been suggested as the most plausible explanation for the paradoxical 55\% greater RTI mortality risk among more privileged ethnic Russian females aged 20-59 years, compared to their native ethnic Kyrgyz peers in the former Soviet republic of Kirgizstan in Central Asia, ${ }^{41}$ as also evinced among Roma women aged 30-60 years in Bulgaria. ${ }^{42}$ Other studies from Israel have also emphasized the unique cultural practices, norms, and 
attitudes as the major contributors to the RTI mortality inequalities across the ethnic Jewish groups of various country-of-origin, yet likely being the least protective for non-Jewish groups, such as ethnic Arabs, notably children and young adults. ${ }^{43,44}$

Our study further failed to detect a statistically significant correlation between women's marital status and RTI mortality. Our finding partially confirms the absence of the mortality gradient between formally and currently married adult drivers in New Zealand, being though at odds with the twofold increased risk for never married people, explained by their more pronounced risk-taking behavior (eg, drinkdriving and not using a seatbelt). ${ }^{45}$ In general, the existing body of literature supports the married peoples' lower likelihood of involvement in fatal traffic crashes, compared to their never or formally married counterparts; however, the direct epidemiological evidence for or against such pattern, particularly among women, is still very scarce. ${ }^{7,10,45}$ As such, the US prospective cohort study among adults aged 18-64 years reported RTI mortality inequalities across all marital categories, with widowed road users exhibiting the highest, two-fold excess risk, relative to currently married ones. ${ }^{11}$ Consistent with this trend, the Swiss longitudinal study, though, documented the highest risk in divorced individuals. ${ }^{36}$ Likewise, in the French cohort study, recent marital separation or divorce, including among middle-aged women, was strongly associated with an elevated risk of a serious traffic crash and even more so with that of at-fault driver crash, likely reflecting the negative impact of stress induced by marital conflict and ensuing inattention or irresponsible behaviors. ${ }^{46}$ Alternatively, the cross-sectional study in South Iran identified young and middle-aged married women to be disproportionately involved in fatal road crashes. ${ }^{47}$ Interestingly, the literature increasingly highlights the upward trend in injuries sustained by pregnant women in traffic crashes, even with the diluted gradient in fatalities between pregnant and non-pregnant women, as evinced in the Swedish national population-based retrospective study. ${ }^{48,49}$ Research suggests the rising number of miles driven by pregnant women and concurrent misuse or underuse of seat belts for fear of harm to their fetus as the main underlying mechanisms behind this trend, making motor vehicle collisions the leading cause of injury-related maternal fatalities and fetal death in the US. ${ }^{48}$ This could be an important area for future investigation in Georgia as well.

Another notable finding of our study pertains to the nonsignificant rural-urban gradient in RTI mortality. Our observation replicates the results from the earlier Norwegian cohort study, disproving the rural-urban disparities in any type of fatal road crashes among young female car occupants aged 16-20 years, ${ }^{50}$ while appears to be at odds with reports from South $\operatorname{Iran}^{47}$ and India, ${ }^{23}$ with the latter indicating $50 \%$ higher risk of premature $(<70$ years) pedestrian death in urban than in rural areas. In support of this trend, available evidence from various contexts, including the FSU, emphasizes urban areas as the persistently higher risk locations for all transport mode injuries, but particularly for severe and fatal pedestrian trauma, likely driven by more intense traffic exposure due to high traffic volume and a roadway hazardous environment (eg, the complexity of the intersections, high levels of on-street parking, amongst others). ${ }^{7,10,13,15}$ This pattern contradicts the previous works from China, ${ }^{51}$ the US ${ }^{11,52,53}$ and New Zealand, ${ }^{40}$ documenting an excess risk of fatal crashes among rural residents, compared to those living in urban areas. Several potential mechanisms have been put forward as the major driving forces behind the predominance of fatalities and more severe injuries on rural roads, namely higher traffic law violations (eg, speeding, drink-driving, seat belt underuse), poor road traffic control and lagging road safety infrastructure (eg, lack of road maintenance, street lighting, signalized intersections, crosswalks, sidewalks, guardrails, etc.), and less crashworthy vehicles, in addition to the delayed and/or lower quality post-crash response and emergency trauma care. ${ }^{10,11,40,51,53}$

Likewise, no consistent relation was evidenced in our research between women's educational qualification and fatal RTI outcomes, which is in line with the earlier research in many contexts, where the educational gradient in safety performance on the road and the resultant fatalities tends to be less steep in women than in men. $3,7,9,10,39$ The same holds true for the cross-national study in nine European developed countries, refuting significant educational disparities in transportation injury mortality among women aged 30-49 in all country settings together and within each one, with the only exception of Finland and Belgium, though exhibiting the weak excess mortality risk among less educated women. ${ }^{54}$ The similar flat educational gradient has been also documented among the adult drivers' cohort in New Zealand. ${ }^{55}$ However, our finding is discordant with the previous evidence showing the excess risk of fatal injuries in undereducated individuals, as seen among Swiss adults, particularly pedestrians (two-fold), ${ }^{36}$ the US female car occupants aged 25-64 (three-fold), ${ }^{39}$ and young (19-40 years) and middle-aged (41-65 years) South Iranian illiterate women, ${ }^{47}$ alongside 
a plethora of other observational studies, suggesting socially patterned exposure and susceptibility to traffic injuries as the most likely mechanisms underpinning reported mortality inequalities. ${ }^{3,7,9,11,43,55,56}$ It has been hypothesized that, apart from higher reliance on unsafe forms of transportation, less educated people may face the attitude and behavioral problems, possibly shaped by their limited knowledge of rules and regulations, precluding them to read and understand road signs or use protective devices, while further instigated by the lack of awareness and poorer appreciation of related risks or ability to translate this information in real actions. ${ }^{7,9,10,39,57}$

Our study, though, confirms the strong positive association between women's employment status and RTI mortality by detecting an excess risk in employed women, compared to their unemployed counterparts. A similar conclusion has been reached in several earlier studies around the world, supporting low-skilled or self-employed workers to be at higher risk of fatal crashes relative to other occupational categories, including those out of the labor force, ${ }^{7,10,55,58}$ as seen in the US for blue collar occupations. ${ }^{11}$ The underlying mechanisms likely to explain this gap is thought to reflect increased exposure to the hazardous traffic environment due to increased travel demand, inferring much longer distances covered and the average time spent daily for work-related driving, traveling, and commuting, coupled with the greater susceptibility to fatigue, exhaustion, and sleepiness, thus lapses in concentration and the resultant adverse safety events. ${ }^{8,58,61}$ Such patterns are of particular relevance to Georgia, where women tend to be overly represented in the informal sector. ${ }^{62,63}$ More worrisomely, while $27 \%$ of the population and $30 \%$ among the poorest $(40 \%)$ in Georgia live in the households headed by women, ${ }^{62,63}$ the earlier review study highlighted that census tracts in the US with reported high-frequency pedestrian injuries had more children living in female-headed households, compared with census tracts with reported low-frequency injuries. ${ }^{10}$ On the other hand, our observation is discordant with the evidence from India, disproving occupational inequalities in pedestrian mortality. ${ }^{23}$ Moreover, the study from South Iran documented the greater involvement of female housekeepers in fatal pedestrian crashes, likely reflecting the gender roles of males and females in this country, with women being far less likely than men to participate in the labor market. ${ }^{47}$

The most striking finding from our study is related to the strong positive effect of accumulated wealth on the odds of road traffic crash, with more affluent women tending to sustain fatal RTI to a greater extent than their less well-off peers.
Nonetheless, several earlier studies from HICs documented improved road safety and lower RTI risk in the most disadvantaged people that have been linked to the less access to vehicles and consequent greater use of much safer public transport, or limited mobility pattern, including for leisure activities or shopping, due to insufficient income. ${ }^{10}$ Furthermore, evidence from the Danish National Travel Survey indicates a highly significant positive effect of higher income on driving speed, inferring that a higher income likely increases the perceived value of time and decreases the actual cost of fines and other speed-dependent user costs, leading more affluent road users to continuously face a trade-off between complying with the rules or gaining time and income by infringing the laws. ${ }^{64}$ Research elsewhere also highlights that aberrant driving behaviors in more privileged drivers may be influenced by the possession of an expensive car, which, as a symbol of prestige, may create a false sense of superiority and autonomy, making them, therefore, far more crash prone than other drivers. ${ }^{65}$ Alternatively, the Norwegian follow-up study among young females aged 16-20 years could not reveal the traffic-related mortality gradient across the family income quartiles. ${ }^{50}$ However, these patterns contradict the general tendency in the existing epidemiological literature, supporting the notion that for most types of traffic injuries, the burden of morbidity and mortality disproportionately falls on people with low SEP (individual material deprivation), as a reflection of the complex interaction of several behavioral (seat belt nonuse, aggressive violations), contextual (areabased physical and socioeconomic deprivation), and vehicular factors (unsafe, less crashworthy vehicles) that is likely exacerbated by the limited accessibility and affordability of highquality medical care, with deep social and economic repercussions. ${ }^{3,711,40}$ Furthermore, some researchers argue that individual SEP may not protect the health of people who are well off when they live in poor environments, meaning that neighborhood-level economic segregation can equally affect all members of a community, irrespective of their individual economic standing. ${ }^{11}$ This seems to be an additional important line of future research.

\section{Limitations}

This study has a number of limitations. One major limitation is its cross-sectional design, which precludes making causal inferences. Second, the observed associations should be interpreted somewhat cautiously due to the relatively small number of road traffic deaths. Further, the role of other potentially relevant explanatory factors could not be ruled out in our analysis, which was confined 
to the variables available in the original data, overall featuring high item non-response rates, except for selected variables $(0-4 \%)$, suggesting thereby no major bias. Further, information on women's socio-demographics in our study was based on respondents' self-reports that may be a subject to social desirability and recall biases. The latter, alongside the other potential biases in our study, could be attributable to the well-established limitations inherent in the PCVA method, likely linked to the instrument design, selection of respondents, variability in interviewers' skills, and physicians' approaches to death certification and coding. ${ }^{66}$ Despite these limitations, the present study, using the nationally representative data, provides important evidence on young women's sociodemographic disparities in RTI mortality, pointing, at least to some extent, to those areas, where interventions might be particularly effective. As major adding to the literature, our results could prove useful in guiding future research and policy action to operationalize equity and effectively enhance the overall level of safety and survival in this most productive and important segment of society.

\section{Conclusion}

To the best of our knowledge, no studies have as yet examined the impact of RTIs on young women's health through the lens of social inequalities in the Georgian and the FSU context. Contributing to the overall limited evidence base in this area, our research identified clear social patterns of RTI mortality in women of reproductive age, yielding important insight into strong independent risk predictors of these unnatural causes of premature death such as being younger, employed, and more privileged. The findings presented here could inform national road safety policies and abatement strategies suitable for transitional countries, with opportunities for targeting or tailoring preventive countermeasures towards the most at-risk groups. This, in turn, will stand to benefit from equity-based, multisectoral, and integrated interventions, with the concerted policy efforts to be essentially focused on improved information and surveillance systems and institutional capacity strengthening for reversing the unabated trend towards inequalities in premature RTI mortality among women during their most productive and reproductive years. Accelerated progress can, however, be achieved through the Safe System approach, based on the Vision Zero framework, promoting better road safety management, safer road networks and mobility, and safer vehicles, as the fundamental pillars of the Global Plan for the Decade of Action for Road Safety. ${ }^{67}$ As one of its five pillars, modification of road user's risky behavior through the effective road safety mass media campaign in combination with other behavioral measures (eg, law enforcement, education, or training), can become a powerful way to persuade the public to behave more safely in traffic. Key to this approach is also efficient and high-quality post-crash response with explicit attention to strengthening emergency and trauma care. Our findings finally call for future comprehensive research, which would be advantageous for further deciphering the differential impact of social determinants on adverse outcomes of road traffic crashes in young adult women, as a vital platform for remedial actions on this predictable and preventable safety hazard.

\section{Acknowledgments}

The authors thank the US International Development Agency (USAID) for funding this study and the Letten Foundation for providing financial support for this work. The authors would like to express their deepest gratitude and appreciation to the Late Professor Babill Stray-Pedersen, without whom this research work would not have been possible. The authors are also grateful to the NCDC\&PH staff and all other contributors to this study. The funding agency had no role in the study design and data collection, data analysis or in the preparation of this manuscript.

\section{Disclosure}

The authors report no conflicts of interest in this work.

\section{References}

1. World Health Organization. Global status report on road safety; 2018. Geneva, Switzerland: World Health Organization. Available from: https://www.who.int/publications-detail/global-status-report-on-roadsafety-2018. Accessed March 11,2019.

2. GBD 2017 Causes of Death Collaborators. Global, regional, and national age-sex-specific mortality for 282 causes of death in 195 countries and territories, 1980-2017: a systematic analysis for the Global Burden of Disease Study 2017. Lancet. 2018;392(10159):1736-1788.

3. Hazen A, Ehiri JE. Road traffic injuries: hidden epidemic in less developed countries. J Natl Med Assoc. 2006;98(1):73-82.

4. Jackisch J, Sethi D, Mitis F, Szymañski T, Arra I. European facts and the Global status report on road safety 2015; 2015. Copenhagen, Denmark: World health Organization Regional Office for Europe. Available from: http://www.euro.who.int/_data/assets/pdf_file/0006/ 293082/European-facts-Global-Status-Report-road-safety-en.pdf?ua= 1. Accessed September 20, 2019.

5. AbouZahr C. Progress and challenges in women's health: an analysis of levels and patterns of mortality and morbidity. Contraception. 2014;90(Suppl 6):S3-S13. doi:10.1016/j.contraception.2014.03.007

6. Beyond the mortality advantage: investigating women's health in Europe. Copenhagen, Denmark: WHO Regional Office for Europe; 2015. Available from: http://www.euro.who.int/en/health-topics/healthdeterminants/gender/publications/2015/beyond-the-mortality-advantage. -investigating-womens-health-in-europe. Accessed May 5, 2017. 
7. Grimm M, Treibich C. Socio-economic determinants of road traffic accident fatalities in low and middle income countries; 2010. Erasmus University Rotterdam. Available from: https:/pdfs.semanticscholar. org/63b0/9ea65933223c600f7ac07e49094fca4b8c72.pdf?_ga= 2.267485966.1225041796.1571845719-1003455218.1544978641. Accessed September 15, 2019.

8. Plasencia A, Borrell C. Reducing socioeconomic inequalities in road traffic injuries: time for a policy agenda. J Epidemiol Community Health. 2001;55(12):853-854. doi:10.1136/jech.55.12.853

9. Laflamme L, Diderichsen F. Social differences in traffic injury risks in childhood and youth - a literature review and research agenda. Inj Prev. 2000;6(4):293-298. doi:10.1136/ip.6.4.293

10. Van den Berghe W. The association between road safety and socioeconomic situation (SES). An international literature review; 2017. Brussels, Belgium: Vias institute - Knowledge Centre Road Safety. Available from: https://www.vias.be/publications/Het\%20verband\% 20tussen\%20SES\%20en\%20verkeersveiligheid/The_association _ between_road_safety_and_socio-economic_situation_(SES).pdf. Accessed October 17, 2019.

11. Cubbin C, LeClere FB, Smith GS. Socioeconomic status and injury mortality: individual and neighbourhood determinants. J Epidemiol Community Health. 2000;54(7):517-524. doi:10.1136/jech.54.7.517

12. He H, Paichadze N, Hyder AA, Bishai D. Economic development and road traffic fatalities in Russia: analysis of federal regions 2004-2011. Int J Epidemiol. 2015;2(1):19. doi:10.1186/s40621-0150051-6

13. Kudryavtsev AV, Nilssen O, Lund J, Grjibovski AM, Ytterstad B. Explaining reduction of pedestrian-motor vehicle crashes in Arkhangelsk, Russia, in 2005-2010. Int J Circumpolar Health. 2012;71(1):19107. doi:10.3402/ijch.v71i0.19107

14. Artikova V, Thompson ME, Platonova E, Pyle GF, Toimatov S. Trends in traffic collisions and injuries in Kyrgyzstan, 2003-2007. Bull World Health Organ. 2011;89(5):345-351. doi:10.2471/BLT.10.084434

15. Chekijian SA, Truzyan N. Practices, attitudes and perceptions toward road safety in Yerevan, Republic of Armenia. Ann Adv Automot Med. 2012;56:191-200.

16. Georgia. WHO statistical profile; 2015. Geneva, Switzerland: World Health Organization. Available from: http://www.who.int/gho/coun tries/geo.pdf?ua=1. Accessed February 3, 2017.

17. World Health Organization. Progress in the prevention of injuries in the WHO European Region: Georgia; 2013. Copenhagen, Denmark: World Health Organization Regional office for Europe. Available from: http://www.euro.who.int/_data/assets/pdf_file/0010/98713/ Georgia.pdf?ua=1. Accessed July 3, 2017.

18. Serbanescu F, Teft M, Shakhnazarova M, Willians D, Berdzuli N, Berg C. Reproductive Age Mortality Study, Georgia 2008 - Part II: Maternal Mortality. Atlanta, GA: Division of Reproductive Health, Centers for Disease Control and Prevention (DRH/CDC); 2009.

19. Lomia N, Berdzuli N, Sturua L, et al. Leading causes of death of women of reproductive age in the Republic of Georgia: findings from the National Reproductive Age Mortality Survey (2014). Int $J$ Women's Health. 2018;10:437-452. doi:10.2147/IJWH.S164053

20. World Health Organization. International statistical classification of diseases and related health problems 10th revision, edition 2010; 2010. Geneva, Switzerland: World Health Organization. Available from: http://apps.who.int/classifications/icd10/browse/ 2010/en. Accessed March 15, 2015.

21. Rutstein SO. The DHS Wealth Index: Approaches for Rural and Urban Areas. Washington, DC: Macro International Inc; 2008.

22. Firth D. Bias reduction of maximum likelihood estimates. Biometrika. 1993;80(1):27-38. doi:10.1093/biomet/80.1.27

23. Hsiao M, Malhotra A, Thakur JS, et al. Road traffic injury mortality and its mechanisms in India: nationally representative mortality survey of 1.1 million homes. BMJ Open. 2013;3(8):e002621. doi:10.1136/bmjopen-2013-002621
24. Oliver GJ, Walter DP, Redmond AD. Are prehospital deaths from trauma and accidental injury preventable? A direct historical comparison to assess what has changed in two decades. Injury. 2017;48 (5):978-984. doi:10.1016/j.injury.2017.01.039

25. Bakke HK, Wisborg T. Rural high north: a high rate of fatal injury and prehospital death. World J Surg. 2011;35:1615-1620.

26. Toroyan T, Peden M. Youth and road safety; 2007. Geneva, Switzerland: World Health Organization. Available from: https:// apps.who.int/iris/bitstream/handle/10665/43607/9241595116_eng. pdf? sequence=1. Accessed October 22, 2019.

27. Sethi D, Racioppi F, Bertollini R. Preventing the leading cause of death in young people in Europe. $J$ Epidemiol Community Health. 2007;61(10):842-843. doi:10.1136/jech.2007.063081

28. Ouimet MC, Pradhan AK, Brooks-Russell A, Ehsani JP, Berbiche D, Simons-Morton BG. Young drivers and their passengers: a systematic review of epidemiological studies on crash risk. J Adolesc Health. 2015;57(1):SS24-35.e6. doi:10.1016/j.jadohealth.2015.03.010

29. Curry AE, Mirman JH, Kallan MJ, Winston FK, Durbin DR. Peer passengers: how do they affect teen crashes? J Adolesc Health. 2012;50(6):588-594. doi:10.1016/j.jadohealth.2011.10.016

30. Fu J, Anderson CL, Dziura JD, Crowley MJ, Vaca FE. Young unlicensed drivers and passenger safety restraint use in U.S. Fatal crashes: concern for risk spillover effect? Ann Adv Automot Med. 2012;56:37-43.

31. Gonzales M, Dickinson M, DiGuiseppi C, Lowenstein S. Student drivers: a study of fatal motor vehicle crashes involving 16-year-olddrivers. Ann Emerg Med. 2005;45(2):140-146. doi:10.1016/j. annemergmed.2004.08.039

32. Hanna CL, Hasselberg M, Laflamme L, Möller J. Road traffic crash circumstances and consequences among young unlicensed drivers: a Swedish cohort study on socioeconomic disparities. BMC Public Health. 2010;10(1):14. doi:10.1186/1471-2458-10-14

33. Diaz EM. Theory of planned behavior and pedestrians' intentions to violate traffic regulations. Transp Res Part F Traffic Psychol Behav. 2002;5(3):169-175. doi:10.1016/S1369-8478(02)00015-3

34. Deba S, Strawdermana L, DuBienb J, Smitha B, Carruthc DW, Garrisonc TM. Evaluating pedestrian behavior at crosswalks: validation of a pedestrian behavior questionnaire for the U.S. population. Accid Anal Prev. 2017;106:191-201. doi:10.1016/j.aap.2017.05.020

35. Lefio Á, Bachelet VC, Jiménez-Paneque R, Gomolán P, Rivas K. A systematic review of the effectiveness of interventions to reduce motor vehicle crashes and their injuries among the general and working populations. Rev Panam Salud Publica. 2018;42:e60.

36. Spoerri A, Egger M, von Elm E, et al. Mortality from road traffic accidents in Switzerland: longitudinal and spatial analyses. Accid Anal Prev. 2011;43(1):40-48. doi:10.1016/j.aap.2010.06.009

37. Hasselberg M, Laflamme L. Road traffic injuries among young car drivers by country of origin and socioeconomic position. Int J Public Health. 2008;53(1):40-45. doi:10.1007/s00038-007-6083-0

38. Stirbu I, Kunst AE, Bos V, van Beeck EF. Injury mortality among ethnic minority groups in the Netherlands. $J$ Epidemiol Community Health. 2006;60(3):249-255. doi:10.1136/jech.2005.037325

39. Braver ER. Race, Hispanic origin, and socioeconomic status in relation to motor vehicle occupant death rates and risk factors among adults. Accid Anal Prev. 2003;35(3):295-309. doi:10.1016/S00014575(01)00106-3

40. Hosking J, Ameratunga S, Exeter D, Stewart J, Bell A. Ethnic, socioeconomic and geographical inequalities in road traffic injury rates in the Auckland region. Aust N Z J Public Health. 2013;37 (2):162-167. doi:10.1111/1753-6405.12034

41. Guillot M, Gavrilova N, Pudrovska T. Understanding the "Russian mortality paradox" in Central Asia: evidence from Kyrgyzstan. Demography. 2011;48(3):1081-1104. doi:10.1007/s13524-011-0036-1

42. Kohler IV, Preston SH. Ethnic and religious differentials in Bulgarian mortality, 1993-1998. Popul Stud (Camb). 2011;65(1):91-113. doi:10.1080/00324728.2010.535554 
43. Factor R, Mahalel D, Yair G. Inter-group differences in road-traffic crash involvement. Accid Anal Prev. 2007;40(6):2000-2007. doi:10.1016/j.aap.2008.08.022

44. Magid A, Leibovitch-Zur S, Baron-Epel O. Increased inequality in mortality from road crashes among Arabs and Jews in Israel. Traffic Inj Prev. 2015;16(1):42-47. doi:10.1080/15389588.2014.908289

45. Whitlock G, Norton R, Clark T, Jackson R, MacMahon S. Motor vehicle driver injury and marital status: a cohort study with prospective and retrospective driver injuries. Inj Prev. 2004;10(1):33-36. doi:10.1136/ip.2003.003020

46. Lagarde E, Chastang JF, Gueguen A, Coeuret-Pellicer M, Chiron M, Lafont S. Emotional stress and traffic accidents: the impact of separation and divorce. Epidemiology. 2004;15(6):762-766. doi:10.1097/ 01.ede.0000142140.77194.ad

47. Lotfi S, Honarvar AR, Gholamzadeh S. Analysis and identification of the hidden relationships between effective factors in the mortality rate caused by road accidents: a case study of Fars Province, Iran. Chin J Traumatol. 2019;22(4):233-239. doi:10.1016/j.cjtee.2018.11.004

48. Vladutiu CJ, Weiss HB. Motor vehicle safety during pregnancy. Am J Lifestyle Med. 2012;6(3):241-249. doi:10.1177/1559827611421304

49. Kvarnstrand L, Milsom I, Lekander T, Druid K, Jacobsson B. Maternal fatalities, fetal and neonatal deaths related to motor vehicle crashes during pregnancy: a national population-based study. Acta Obstet Gynecol Scand. 2008;87(9):946-952. doi:10.1080/000163 40802302184

50. Kristensen P, Kristiansen T, Rehn M, Gravseth HM, Bjerkedal T. Social inequalities in road traffic deaths at age 16-20 years among all 611,654 Norwegians born between 1967 and 1976: a multilevel analysis. Inj Prev. 2012;18(1):3-9. doi:10.1136/ip.2011.031682

51. Wang L, Ning P, Yin P, et al. Road traffic mortality in China: analysis of national surveillance data from 2006 to 2016. Lancet Public Health. 2019;4(5):e245-e255. doi:10.1016/S2468-2667(19)30057-X

52. Beck LF, Downs J, Stevens MR, Sauber-Schatz EK. Rural and urban differences in passenger-vehicle-occupant deaths and seat belt use among adults - United States, 2014. MMWR Surveill Summ. 2017;66 (17):1-13. doi:10.15585/mmwr.ss6617a1

53. Zwerling C, Peek-Asa C, Whitten PS, Choi SW, Sprince NL, Jones MP. Fatal motor vehicle crashes in rural and urban areas: decomposing rates into contributing factors. Inj Prev. 2005;11 (1):24-28. doi:10.1136/ip.2004.005959

54. Borrell C, Plasència A, Huisman M, et al. Education level inequalities and transportation injury mortality in the middle aged and elderly in European settings. Inj Prev. 2005;11(3):138-142. doi:10.1136/ip.2004. 006346
55. Whitlock G, Norton R, Clark T, Pledger M, Jackson R, MacMahon S. Motor vehicle driver injury and socioeconomic status: a cohort study with prospective and retrospective driver injuries. J Epidemiol Community Health. 2003;57(7):512-516. doi:10.1136/jech.57.7.512

56. Harper S, Charters TJ, Strumpf EC. Trends in socioeconomic inequalities in motor vehicle accident deaths in the United States, 1995-2010. Am J Epidemiol. 2015;182(7):606-614. doi:10.1093/aje/kwv099

57. Forjuoh S. Traffic-related injury prevention interventions for low-income countries. Int J Inj Contr Saf Promot. 2003;10(1-2):109-118. doi:10.1076/icsp.10.1.109.14115

58. Sadeghi-Bazargani H, Samadirad B, Shahedifar N, Golestani M. Epidemiology of road traffic injury fatalities among car users: a study based on forensic medicine data in East Azerbaijan of Iran. Bull Emerg Trauma. 2018;6(2):146-154. doi:10.29252/beat-060209

59. Smith AP. A UK survey of driving behaviour, fatigue, risk taking and road traffic accidents. BMJ Open. 2016;6(8):e011461. doi:10.1136/ bmjopen-2016-011461

60. Barger LK, Cade BE, Ayas NT, et al. Extended work shifts and the risk of motor vehicle crashes among interns. N Engl J Med. 2005;352 (2):125-134. doi:10.1056/NEJMoa041401

61. Chiron M, Bernard M, Lafont S, et al. Tiring job and work related injury road crashes in the GAZEL cohort. Accid Anal Prev. 2008;40 (3):1096-1104. doi:10.1016/j.aap.2007.12.001

62. National Statistics Office of Georgia. Available from: http://www. geostat.ge. Accessed November 23, 2019.

63. United Nations Population Fund. Population situation analysis (PSA) 2014: final report; 2014. Tbilisi, Georgia: United Nations Population Fund. Available from: https://georgia.unfpa.org/sites/default/files/pubpdf/PSA\%20_Final\%20Print\%20version_0.pdf. Accessed October 15, 2018.

64. Fosgerau M. Speed and Income. J Transp Econ Policy. 2005;39 (2):225-240

65. Banakar R, Nasrolahi Fard S. Driving dangerously: law, culture and driving habits in Iran. Br J Middle East Stud. 2012;39(2):241-257. doi:10.1080/13530194.2012.711039

66. Lozano R, Lopez AD, Atkinson C, Naghavi M, Flaxman AD, Murray CJ. Population Health Metrics Research Consortium (PHMRC). Performance of physician-certified verbal autopsies: multisite validation study using clinical diagnostic gold standards. Popul Health Metr. 2011;9(1):32. doi:10.1186/1478-7954-9-32

67. The global plan for a decade of action for road safety 2011-2020; 2010. New York: United Nations Road Safety Collaboration. Available from: http://www.who.int/roadsafety/decade_of_action/ plan/en/. Accessed November 26, 2019.

\section{Publish your work in this journal}

The International Journal of Women's Health is an international, peerreviewed open-access journal publishing original research, reports, editorials, reviews and commentaries on all aspects of women's healthcare including gynecology, obstetrics, and breast cancer. The manuscript management system is completely online and includes a very quick and fair peer-review system, which is all easy to use Visit http://www.dovepress.com/testimonials.php to read real quotes from published authors. 